\title{
Quantitative Geomorphological Parameters Analysis for the Aynalem- Illala Streams, Tigray, Northern Ethiopia
}

Fethangest Woldemariyam Tesema ${ }^{1 *}$, Gebrerufael Hailu Kahsay ${ }^{2}$ and Berihu Abadi Berhe ${ }^{1}$

${ }^{1}$ School of Earth Sciences, College of Natural and Computational Sciences, P.O. Box 231, Mekelle University, Mekelle, Ethiopia (*Fethangest17@gmail.com).

${ }^{2}$ Institute of Geo-information and Earth observation Sciences, Mekelle University P.O. Box231, Mekelle, Ethiopia.

\begin{abstract}
Morphometric analysis is the measurement and mathematical analysis of the configuration of the surface, shape, and dimension of landforms. The objective of this study is to characterize the Aynalem and Illala streams using the morphometric parameter. The topographic map at a scale of 1:50,000 taken from the Ethiopian National Mapping Agency was used to characterize the linear and areal aspects. ASTER Digital Elevation Model with $10 \mathrm{~m}$ resolution was used to characterize the relief aspect. The Arc GIS 10.4.1 was used during the morphometric analysis. The analysis result of the streams is summarized based on the linear, areal, and relief aspects. The area is characterized by a dendritic drainage pattern which is characteristics of massive hard rock terrain. The Aynalem and Illala streams are 4th and 5th order streams. Considering the number of streams in the Aynalem $(75.81 \%)$ and Illala $(74.66 \%)$ is composed of first-order streams that indicate a flashy flood and the mean bifurcation value of Aynalem (6.8) and Illala (4.7) shows that the Aynalem area is more structurally affected than Illala but both show less stream integration. The analysis of areal aspects such as elongation ratio, circularity ratio, and form factor has indicated that both streams are characterized as elongated streams, this implies that both streams are flowing in heterogeneous rock material, presences of structural effect, and slow runoff discharge. The other areal aspect such as drainage density, stream frequency, infiltration number, and length of overland flow all show smaller values in both streams. This implies that the streams are characterized by a relatively permeable rock material with a higher infiltration capacity. The relief aspect of the Aynalem and Illala was also analyzed using basin relief, relief ratio, ruggedness number, hypsometric curves, and Hypsometric integral. The streams are characterized by a lower relief ratio and ruggedness number which implies a relatively flat slope and lower relief. The hypsometric curves and the Hypsometric Integral of the streams indicate that the Aynalem and Illala are at the maturity stage. This shows the area is characterized by higher erosion but less affected by recent structures. Based on the morphometric parameter analysis result it is possible to conclude that the stream development is dependent on the topography and geology of the study area and both streams show similar morphometric character.
\end{abstract}

Keywords: Hydrogeology, Morphometric analysis, Aynalem, Illala, Tigray, Ethiopia.

\section{INTRODUCTION}

The town of Mekelle gets most of its water supply from the groundwater system of the Illala catchment and the Aynalem well field. The town is highly affected by water supply shortage for 
its daily consumption. The groundwater system of Aynalem well filed is deteriorating from the uncontrolled extraction of water through wells, fast population growth and Urbanization (WWDSE, 2007; Gebre et al., 2015; Fethangest, 2016).

The ever increasing demand of water in the town realizes the need of different methods and approaches to increase the understanding of the groundwater system, which enhances the use and management of the groundwater potential. Characterizing drainage basin of an area using quantitative morphometric analysis can provide information on the hydrology and groundwater potential of the basin (Wisler and Brater, 1959; Kirkby, 1976; Venkateswaran et al., 2012).

Morphometric may be defined as the measurement and mathematical analysis of the configuration of the earth's surface and the shape and dimensions of its landforms (Clarke, 1966). One of the central problems of hydrology is the correlation of the hydrologic characteristics of a drainage basin with its morphology, soil, and vegetation. The river pattern and drainage network has been studied by different researchers for the reason that the drainage pattern is the reflection of the tectonic activity and geological structures (Abrahams and Flint, 1983; Burbank, 1992), erosional mechanisms (Dunne, 1980), and climate (Gregory, 1976; Daniel, 1981).

The quantitative analysis of morphometric parameters is found to be effective in river basin assessment, watershed prioritization for soil and water conservation and natural resources management at watershed level (Biswas et al., 1999; Panda and Sukumar, 2010; Nag and Lahiri, 2011) and have played a vital role in hydrogeological studies to understand the occurrence, distribution, and movement of water, geology and structure of the basin (Rao et al., 2017). Morphometric analysis of the river basin is a quantitative representation of a basin and provides information about the characteristics of the drainage system, the topographic pattern of earth's surface, the shape and dimension of its landforms, and it is imperative to assess and comprehend the role of a basin dynamics (Parakash et al., 2019).

This paper computes the basin morphometric characteristics for various parameters and evaluate its impact on the groundwater system for Aynalem-Illala area. This includes quantifying morphometric parameters such as Linear, areal, and relief aspects of the Aynalem-Illala basins.

\subsection{Study Area}

Aynalem-Illala area is located in Tigray region in the northern part of the country, about $783 \mathrm{~km}$ north of Addis Ababa. It is bounded by the grid $1539836 \mathrm{mN}$ to $1572495 \mathrm{mN}$ and $535912 \mathrm{mE}$ to 
$565675 \mathrm{mE}$ UTM zone of $37 \mathrm{~N}$. It covers a total area of $443 \mathrm{~km} 2$ (Fig 1). The area is accessible by asphalt Addis Ababa-Mekelle main road.

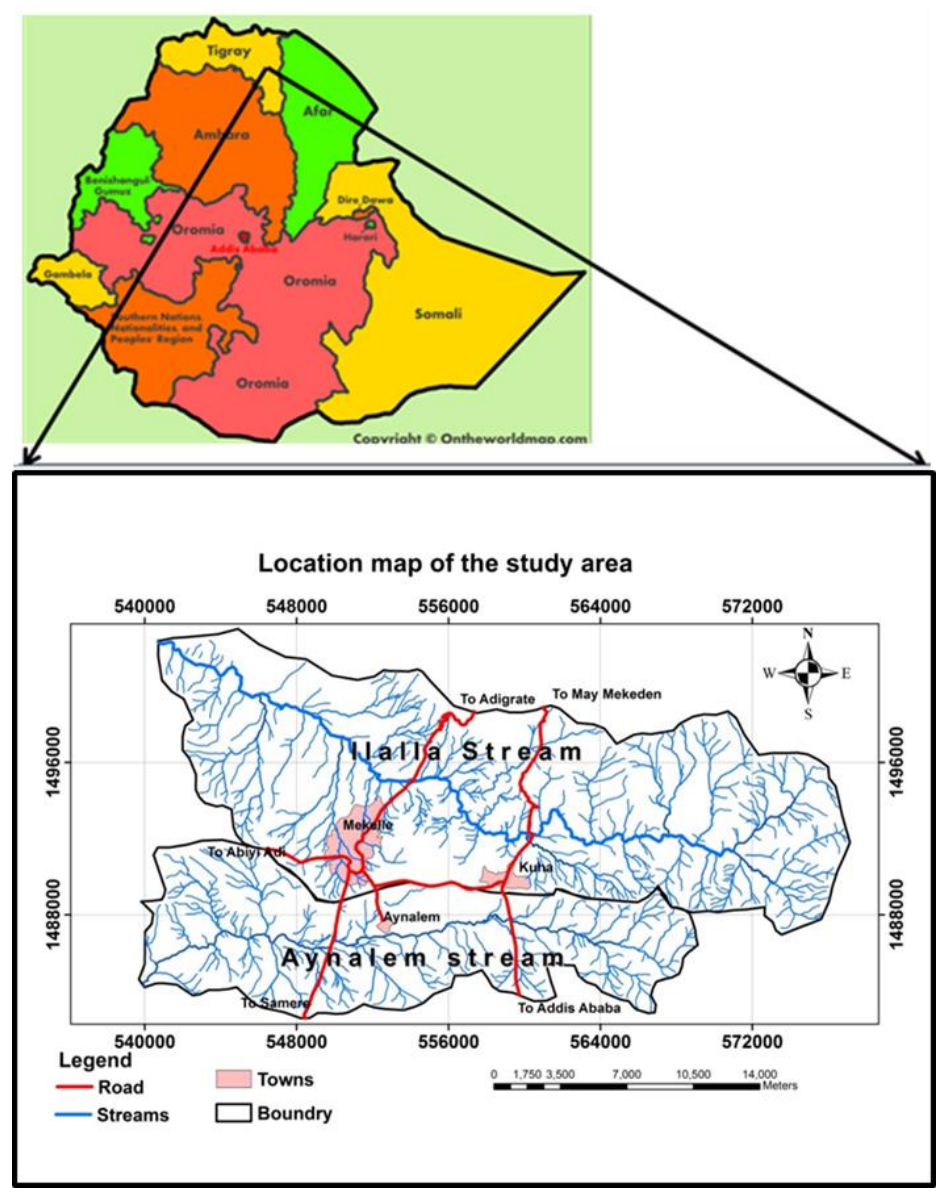

Figure 1. Location map of the Study area.

Generally, the area has a semi-arid climate with little or no variation. The average daily temperature is $24^{\circ} \mathrm{C}$ to $28^{\circ} \mathrm{C}$ in January. The maximum daily temperature may go as high as $30^{\circ} \mathrm{C}$. The mean annual temperature ranges from $15^{\circ} \mathrm{C}$ to $16^{\circ} \mathrm{C}$ cover the central part. There are two rainy seasons, March to April and June to September. Most of the annual rainfall occurs during July and August. The area receives an average annual rainfall of 670.3mm (Teklay, 2006).

The different soil types in the study area are classified based on the grain size distribution. According to the (USDA, 1999) soil classification method, the dominant soil types are classified into four: Sandy loam, silty loam, and clay loam and clay soils. The steep cliffs are dominated by sandy loam and silty loam soils, whereas the clay loam and clay soils occupy the flat and relatively gentle terrains of the area. The land use and land cover of the study area is categorized as 
intensively cultivated agricultural land, grazing land, village settlement, reforestation and urban land (Teklay, 2006).

\subsection{Geology}

\subsubsection{Regional Geology}

The geology of the region has been studied by many researchers for the last five decades. The studies has witnessed the regional geology of the area includes four main rock complexes built up the geology of the region. These are, from the oldest to the youngest; metamorphic and intrusive rocks of the Precambrian basement, Paleozoic clastic rocks and Mesozoic sedimentary rocks (Levitte, 1970; Beyth and Shachnai, 1970; Beyth, 1971,1972; Kazmin, 1972; Bosellini et al., 1997; Garland, 1980; Worash and Valera, 2001; Tesfamichael et al., 2010, 2017).

The structures in the region are dominantly controlled by a system of sets of normal faults (Levitte, 1970). In the Mekelle outlier there are two main fault systems running in the NW-SE and NE-SW (Levitte, 1970; Tesfaye and Gebretsadik, 1979). Under, the first category the Wukro, Mekelle, Chelekot and Fuicea Mariam fault belts are included; under the second category the rift valley faults are included and the NNE-SSW Rift Valley fault system forming the escarpment and the Danakil depression.

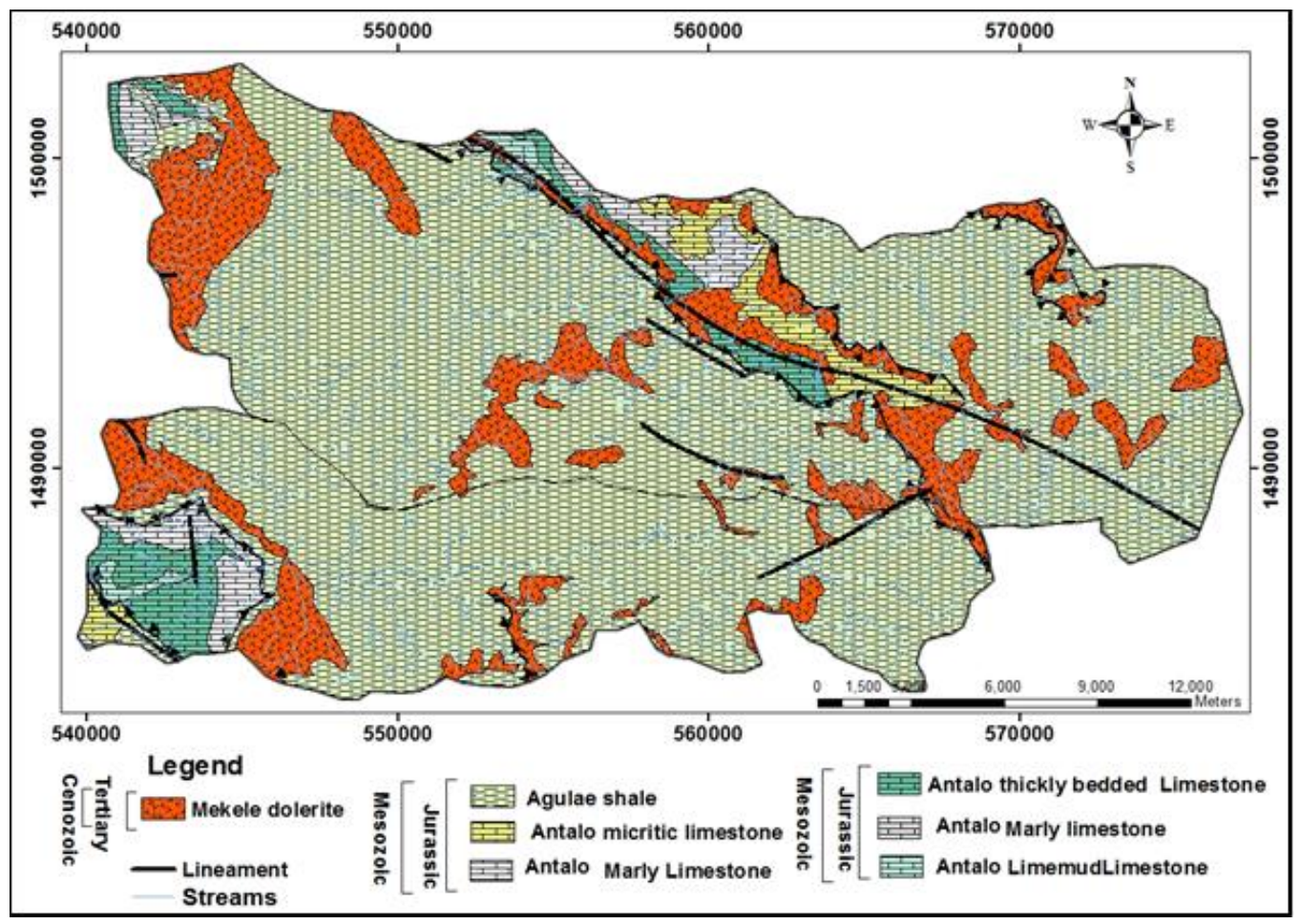

Figure 2. Geology of the study area. 


\subsubsection{Local Geology}

The local geology of the area was mapped at a scale of 1:50,000 in the study area six lithological units are available. The rock units found in the study area from the youngest to the oldest are dolerite, shale, pink-grey micritic limestone, thickly bedded limestone, marly and limestone and lime mud limestone (Fig 2).

\subsubsection{Dolerite}

The vicinity of Mekelle is penetrated by many basaltic intrusions most of which are sills, from 0.5$30 \mathrm{~m}$ wide dykes and small stocks are also common (Levitte, 1970). The rocks are black, fine grained to medium grained, and hard. Exposures are jointed vertically and horizontally and the blocks thus formed are weathered by exfoliation. The whole section is intruded from the basement to the top of Emba Areadom Formations (Levitte, 1970). According to Levitte (1970), the most preferred horizon by the dolerite intrusion is the Agulae Shale Formation which is very soft and has less overburden cover (shallow) than similarly soft Formations that are much deeper. It is penetrated by many sills mostly as thick as $50-100 \mathrm{~m}$.

\subsubsection{Shale}

It is light greyish green calcareous mudstone, yellow conquina limestone grading upward into finely laminated dark limestone. The Agulae Shale Formation is the upper most formation in the limestone sequence. It is overlain by the Emba Aradom Formation. It is composed of grey, green and black shale, marl and clay, interlaminated with finely crystalline black limestone. Some thin beds of gypsum and dolomite, sequences contain a few beds of yellow coquina. It has a thickness of 60-250 m (Levitte, 1970). Dolerite dykes and sills have traversed the unit in various directions, mainly in the vicinity of the study area, caused complete dismembering of the rock units. In a heterogeneous sedimentary sequence, thin incompetent beds, such as shale, will be more intensely fractured as compared with thicker units of strong and resistant formations such as mudstones. Within the units of the same lithology an increase in fracture spacing with depth is observed.

\subsubsection{Limestone}

This unit is quite widespread and shows lot of variation. It is described as pink and grey colored micritic limestone, thickly bedded limestone, marly limestone and lime mud.

Pink and grey micritic limestone

The rock shows shades of pink, grey white and rarely black and is mostly micritic with sporadic thin beds of marl and bioclastic beds. At places, it is massive and hard, and thinly laminated with 
brittle behavior (Fig 2). The rock is highly variable exposed thickness ranging from few meters to more than 40 meters. The relative increase in the thickness of the unit in some sections is assumed to be due to faulting.

Antalo thickly bedded limestone

It is medium to thickly bedded $(30-100 \mathrm{~cm})$, grayish white to creamy, micritic limestone containing upto $5 \%$ fossil fragments less than a $\mathrm{cm}$ in diameter. This is succeeded by thin to medium thick, $3-30 \mathrm{~cm}$, bedded dull gray biomicrite and oolite beds locally grading into friable white lime mudstone. The content of fossil fragments and oolites varies between 5-15\% with a maximum diameter of $1 \mathrm{~cm}$ and $2 \mathrm{~mm}$ respectively. The upper member is medium to thickly bedded (30$100 \mathrm{~cm}$ ) grey to white micritic and oolitic limestone with alternation of few $\mathrm{mm}$ thick bioclastic limestone between the main beds. It forms moderate to steep cliff about 10-15m high.

Marly limestone

Occur as layers and show lenticular bedding. In this section, the upper part $(10 \mathrm{~m})$ is represented by thin to medium thick, bedded, grey and light brown marl and bioclastic limestone. Some bioclasts show alteration to red powder, ochre.

In the northern Mekelle section, the transition from unit Antalo greyish white-creamy medium to thickly bedded limestone to Antalo interbedded light brown marl, white gypsum and limestone is not clearly noted presumably due to erosion. Fragmental and blocky exposures at higher grounds indicate the occurrence of medium to thickly bedded brown bioclastic limestone and oolitic limestone. The bioclasic limestone closely resembles the limestone bed in the lower sequence observed in the Giba Section. In this case, the bioclasts are abundant (30-40\%) and big in size $(3 \mathrm{~cm})$. The intercalating oolitic limestone contains upto $25 \%$ oolite that are $1-3 \mathrm{~mm}$ in diameter. Most bioclasts show recrystallization to calcite mineral aggregates. Close to May Mekedan the upper member of the unit consists of light brown lenticularly bedded (3-5cm), marl (2m) topped by grey brown, thickly bedded oolitic bioclastic limestone $(4 \mathrm{~m})$. The limestone is highly compact such that it has been mined for dimension stone. This layer also shows irregular karastic features along river beds.

Calcarious Limestone

Light brown lime mudstone and bioclastic calcarenite, locally with chert, alternating with marl and marly limestone; silty-arenaceous limestone at the base. The transition from this unit to the Adigrate sandstone is marked by fragmental outcrop of grey-brown coquina limestone. There are 
three layers, the lower member contains $15-30 \%$ fossil fragments that are few $\mathrm{mm}$ to $6 \mathrm{~cm}$ and rarely $1 \mathrm{~cm}$ in diameter. The middle member consists of alternation of thickly bedded $(30-100 \mathrm{~cm})$ grey green/olive mudstone and grey brown bioclastic limestone. The upper most member of the unit is dominated by black, thinly laminated micritic limestone with some fragmental grey brown bioclastic limestone.

\section{METHODOLOGY}

The drainage map of the study area was constructed using a survey map of Ethiopian toposheet on a 1:50,000 scale and validated using the spot image and contour crenulation as much as possible. Large scale maps like 1:50,000 may produce more accurate results than the small scale maps because finger-tip tributaries and rill are correctly depicted on such maps. The morphometric parameters of the two streams have been determined using Arc GIS 10.4. GIS platform is ideal for morphometric analysis because of its potency in processing and quantifying topographic data (Altaf et al., 2013; Prakash et al., 2016).

The evaluated morphometric parameters were grouped as linear, relief, and areal aspects. Based on the drainage order, both drainage networks were classified into different orders using the Strahler (1952b) method. A quantitative description of the drainage network, basin characteristics, and analysis has been carried out for the Aynalem and Ilalla streams. Basic parameters like the number and lengths of streams of a different order, drainage area, basin perimeter, and maximum basin lengths and width and maximum and minimum elevation were calculated after building the drainage layer in GIS software (Fig 3). Using these different basic parameters the linear, areal, and relief aspects of the Aynalem and Ilallla streams catchments are calculated. From the linear aspects which include mean stream length, stream length ratio, the bifurcation ration using the formula in table 1. Similarly, using the basic parameters the areal aspects such as elongation ratio, circularity ratio, form factor, drainage density, stream frequency, infiltration number, length of overland flow, and drainage texture are also calculated. Finally, the relief aspect of the two streams such as basin relief, relief ratio, ruggedness number, relative relief, and the hypsometric integral and hypsometric curve is also calculated using the formula listed in table1.

Hypsometric curve of the streams was obtained by plotting the relative area along the horizontal and relative elevation along the vertical line of the Cartesian coordinate. The relative area is obtained as a ratio of the area above a particular contour to the total area of the watershed 
encompassing the outlet. Considering the watershed area to be bounded by vertical sides and a horizontal base plane passing through the outlet, the relative elevation is calculated as the ratio of the height of a given contour (h) from the base plane to the maximum basin elevation $(\mathrm{H})$ (up to the most remote point of the watershed from the outlet (Sarangi, 2001; Reitter et al., 2002). Then, the curve was prepared in Microsoft EXCEL 2000.

Table 1. Formulas used to calculate the different Morphometric parameters.

\begin{tabular}{|lcl|}
\hline Linear Aspect & Definition & Sources \\
\hline Stream order (u) & Hierarchical & Strahler, 1957 \\
\hline Stream Number (Nu) & Total number of stream of order u & Horton, 1945 \\
\hline Stream Length (Lu) $\mathrm{km}$ & Total stream length of order u & Horton, 1945 \\
\hline Mean Stream Length (Lsm) & $L s m={ }_{u} / N_{u}$ & Strahler, 1957 \\
\hline Stream Length Ratio (RI) & $R I=\frac{N_{u}}{N_{n-1}}$ & Horton, 1945 \\
\hline Bifurcation Ratio & $R I=\frac{N_{u}}{N_{n+1}}$ & Horton, 1945 \\
\hline Areal Aspect & & \\
\hline Elongation Ratio (Re) & $R e=1.128 \sqrt{A / L_{b}}$ & Schumm, 1956 \\
\hline Circularity Ratio (Rc) & $R_{c}=4 \pi A / P^{2}$ & Miller, 1953 \\
\hline Form Factor (Rf) & $R_{f}=A / L b^{2}$ & Horton, 1945 \\
\hline Drainage Density (Dd) & $D_{d}=\sum \frac{L_{t}}{A}$ & Horton, 1945 \\
\hline Stream Frequency (Fs) & $F_{s}=\frac{N_{t}}{A}$ & Horton, 1945 \\
\hline Infiltration number (If) & $I F=D_{d} * F_{S}$ & Smith,1950 \\
\hline Length of overland flow (Lg) & $L_{g}=1 / 2 D_{d}$ & Horton, 1945 \\
\hline Drainage texture (Dt) & $D_{t}=D_{d} * F_{S}$ & Smith, 1950 \\
\hline Relief Aspect & & \\
\hline Basin Relief (H) & $H=h_{\max }-h_{\min }$ & Schumm, 1956 \\
\hline Relief Ratio (Rh) & $R_{h}=H / L_{b}$ & Schumm, 1956 \\
\hline Ruggedness Number (Rn) & $R_{n}=H * D_{d}$ & Strahler ,1968 \\
\hline Relative relief (Rhp) & $R_{h p}=H / L_{b}$ & Melton,1957 \\
\hline Hypsometric Integral & $H I=h_{m e a n}-h_{m i n} / h_{\max }-h_{m i n}$ & $\begin{array}{l}\text { Pike } \\
\text { Wilson, 1971 }\end{array}$ \\
\hline
\end{tabular}




\section{RESULT AND DISCUSSION}

The basic parameters such as stream numbers, stream length, catchment area, catchment perimeter, basin length, and minimum and maximum elevation of the catchment were derived from topomap and DEM (Table 2). These basic parameters are used in calculating linear, areal and relief aspects.

Table 2. The basic morphometric parameters of Aynalem and Illala streams.

\begin{tabular}{|lllllll|}
\hline $\begin{array}{l}\text { Basin } \\
\text { Name }\end{array}$ & $\begin{array}{l}\text { Perimeter }(\boldsymbol{P}) \\
(\boldsymbol{m})\end{array}$ & $\begin{array}{l}\text { Basin } \\
\text { Length }(\mathrm{Lb}) \\
(\boldsymbol{m})\end{array}$ & $\begin{array}{l}\text { Basin } \\
\text { Width }(\boldsymbol{m})\end{array}$ & $\begin{array}{l}\text { Basin } \\
\text { Area }(\boldsymbol{A}) \\
\left(\mathbf{k m}^{2}\right)\end{array}$ & $\begin{array}{l}\text { Maximum } \\
\text { basin Height } \\
(\text { hmax })(\boldsymbol{m})\end{array}$ & $\begin{array}{l}\text { Minimum } \\
\text { Basin } \\
\text { Height } \\
(\boldsymbol{h m i n})(\boldsymbol{m})\end{array}$ \\
\hline Aynalem & 79.21 & 29.00 & & 169.41 & 2520 & 1770 \\
\hline Illala & 95.48 & 37.44 & & 341.38 & 2560 & 1740 \\
\hline
\end{tabular}

\subsection{Linear Properties of the Aynalem and Illala Streams}

\subsubsection{Stream Order (u)}

Stream ordering is the process of classifying the tributaries and the main river in an orderly manner. In this study the stream ordering has been made based on Strahelr (1952) method of stream ordering. The classification of streams based on the number and type of tributary junctions, has proven to be a useful indicator of stream size, discharge, and drainage area (Strahler, 1957). Result of the analysis shows that the order arrangement the Aynalem and Illala streams have fourth and fifth- order respectively (Fig 3). The similarity in stream frequency in each of the stream order is the result of similar physiography, geology and structure.

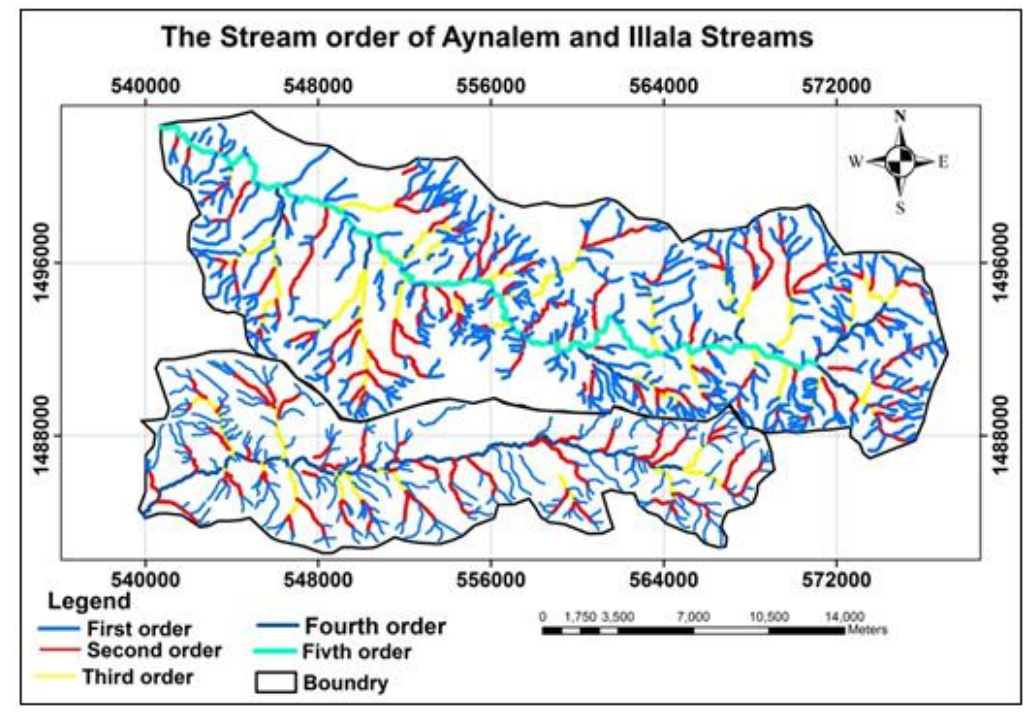

Figure 3. The stream order of the Aynalem and Illala Streams. 


\subsubsection{Stream Number (Nu)}

According to various authors including Horton (1945) and Strahler (1952b), the order of the basins and number of streams has an inverse relationship. In this study, the streams number $(\mathrm{Nu})$ has been plotted against the stream orders on a graph paper with stream number on a logarithmic scale and the order is on the arithmetic scale. The result indicates that there is an inverse relationship between the stream number and stream order (Fig. 3). This is in line with Horton's law of stream numbers, which states that the number of stream segments of each order form inverse geometric sequences with order number. The number of streams of each order of the Aynalem and Illala streams is given in (Table 3).

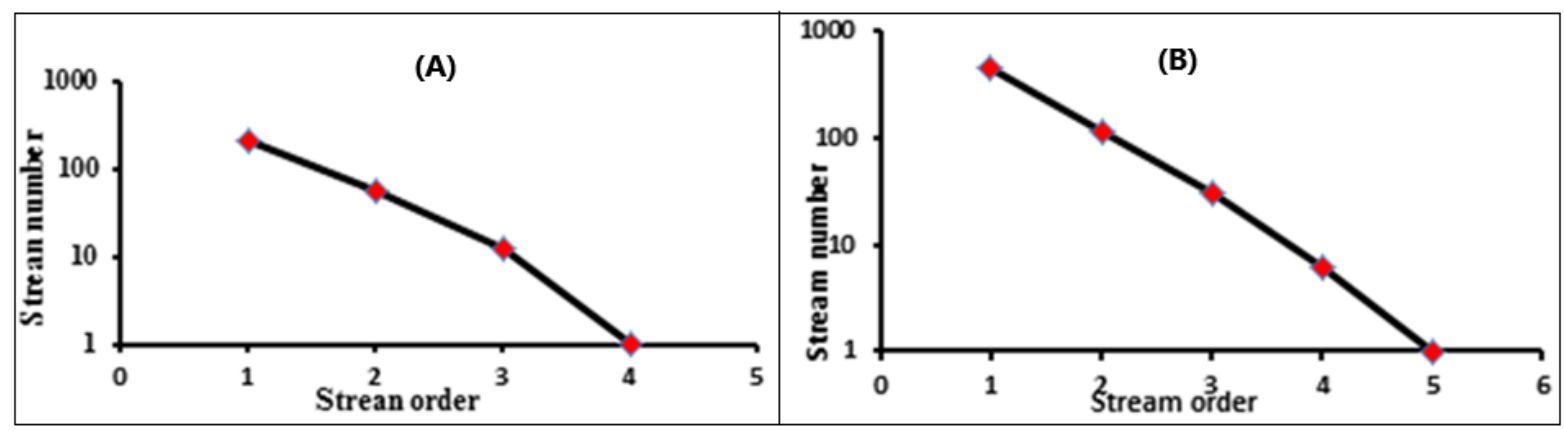

Figure 4. The stream order versus stream number a. Aynalem, b. Illala.

\subsubsection{Stream Length $(\mathrm{Lu})$}

Stream length is the total length of stream segments in each order Horton (1945) and Strahler, (1952b) described stream length measures the mean length of a stream in each order, it can be found by dividing the total length of all streams in each order by the number of stream order of that order. Accordingly, the total stream length of each and mean stream length of each order of the two basins (Aynalem and Illala) has been calculated (Table 1). Ali et al. (2017) has indicated that the stream length varies depending on the permeability of the geologic formation i.e. with permeable geologic formation few and longer streams are created and in less permeable geologic formation the streams become short and relatively much in number.

\subsubsection{Mean Stream Length (Lsm)}

It is the ratio between the total stream lengths of order $u$ to the total number of stream segments of order $u$. It is a property characterizing the size aspect of the drainage network and its linked surface (Strahler, 1957). The analysis result of the mean stream length for Aynalem stream varies between 0.82-30.03 and Illala 0.72-42.92 (Table 3). The analysis result shows that the mean stream length 
increases with increase stream order. If the bedrock and formation is permeable then small number of relative longer streams is formed, while a large number of streams of smaller length are developed, where the bedrocks and formation are less permeable (Thomas et al., 2011). Based on the result analysis Aynalem area is more permeable than the Illala area.

\subsubsection{Stream Length Ratio}

The stream length ratio is the ratio between the mean stream lengths of a given order to the stream length of the lower order (Horton, 1945). It has an important relationship with the surface flow discharge and erosional stage of the basin. The stream length ratio was calculated and the result shows that the Ayanalem and Illala stream length ratio mean values are 0.7 and 5.0 respectively (Table 3).

\subsubsection{Bifurcation Ratio $(R b)$}

It is the ratio between the number of streams in the given order to the number of streams to the next order (Horton, 1945; Strahler, 1952b; Schumm, 1956). Bifurcation ratio indicates the degree of stream network integration with lower value indicates higher integration, it shows lower value in the flat rolling drainage system and higher value if the drainage system is structurally controlled area (Horton, 1945). The results of the analysis show that the average bifurcation ratio, for the Aynalem and Illala is 6.8 and 4.7 respectively (Table 3). The results also show that the drainage network of the Aynalem area is structurally controlled and there is less integration between the streams of different orders. But the Illala area is relatively less structurally affected. If the area is not structurally affected, commonly the mean Rb value ranges from 3.0 to 5.0 (Strahler, 1964). The relatively high bifurcation ratio indicates a potential for flash flooding during storm events. The lower bifurcation ratio values are characteristics of the watershed, which has suffered less structural disturbances and the drainage pattern has not been distorted by the structural disturbances.

Table 3. Result of stream Length, mean stream length and Stream ratio.

\begin{tabular}{|lllllllllll|}
\hline \multirow{3}{*}{ Order } & \multicolumn{2}{l}{ Stream Number } & \multicolumn{2}{l}{ Stream Length } & Mean Stream Length & \multicolumn{2}{l|}{ Stream Length Ratio } & \multicolumn{2}{c|}{ Bifurcation Ratio } \\
\cline { 2 - 11 } & Aynalem & Illala & Aynalem & Illala & Aynalem & Illala & Aynalem & Illala & Aynalem & Illala \\
\hline $1^{\text {st }}$ & 210 & 442 & 172.5 & 316.4 & 0.82 & 0.72 & 1.55 & 1.7 & 3.9 & 3.91 \\
\hline $2^{\text {nd }}$ & 54 & 113 & 68.9 & 137.1 & 1.28 & 1.21 & 1.51 & 2.0 & 4.5 & 3.77 \\
\hline $3^{\text {th }}$ & 12 & 30 & 23.0 & 72.3 & 1.92 & 2.41 & 16.13 & 1.1 & 12 & 5 \\
\hline $4^{\text {th }}$ & 1 & 6 & 31. & 16.9 & 31.0 & 2.8 & & 15.3 & & 6 \\
\hline $5^{\text {th }}$ & & 1 & & 42.9 & & 42.3 & & & & \\
\hline
\end{tabular}




\subsection{Areal Properties of the Aynalem and Illala Basins}

The areal aspects of the two streams calculated are elongation ratio, circulation ratio, form factor, drainage density, stream frequency, and infiltration ratio. Elongation ratio, circularity ratio, and form are parameters used to characterize the shape of the basins. The shape of the basin governs the rate at which the water is supplied to the main channel and is important from a hydrological point of view.

\subsubsection{Elongation Ratio (Re)}

The shape of any basin is expressed by the elongation ratio Re which is defined as the ratio of the diameter of a circle of the same area as the basin to the maximum length of the basin (Schumm, 1956). Normally this ratio varies between 0.6 and 1.0 over a wide variety of climatic and geologic types. Values near to 1 are typical of regions of low relief or the shape of the drainage basin approaches a circle. Values close to 1.0 are typical of regions of very low relief, whereas values in the range $0.6-0.8$ are usually associated with high relief. The elongation ratio of the Aynalem and Illala streams is 0.51 and 0.56 respectively (Table 4). Based on Strahler (1964) elongation classification both basins belong to the elongated basin. As the relief increases, discharge and surface runoff increase implying lower infiltration to groundwater: The infiltration increases with decreasing elongation ratio.

\subsubsection{Circularity Ratio (Rc)}

Basin circularity Rc is the shape measure, which is related to the stream flow. Circularity within a basin is independent of the order. However, the nearness of circularity tends to be more in lowerorder basins than in a higher-order basin. Miller (1953) defined dimensionless circularity ratio Rc as the ratio of the basin area A to the area of a circle Ac having the same perimeter as the basin. The analysis result of the circularity ratio for the Aynalem and Illala streams is 0.34 and 0.43 respectively (Table 4). According to Strahler (1952b); and Liaqat et al. (2017) the circularity ratio is affected by geology and structure and slope. The analysis result indicates that the two basins are elongated and they are structurally controlled streams. This is true as the area which is affected by the long-running normal fault called the Mekelle Fault. Miller (1953) has also indicated that a circularity ratio between 0.6 and 0.7 shows that the stream is flowing on homogeneous geologic materials. In our case, the result is out of the specified range which indicates that the streams are flowing in heterogeneous geologic units that include a stratified Mesozoic sedimentary succession disturbed by later coming dolerite unit. 


\subsubsection{Form Factor (Rf)}

This is the ratio of the basin area to the square of basin length (Horton, 1932). The form factor Rf is a quantitative expression of drainage basin outline form (Horton, 1945), which is a dimensionless ratio of basin area $\left(A_{b}\right)$ to the square of the basin length $\left(L_{b}\right)$. The form factor that indicates the shape or outline form of a drainage basin may conceivably affect stream discharge characteristics.

The calculated form factor for the Aynalem and Illala basins is 0.2 and 0.24 respectively (Table 4). Results of the analysis shows a highly elongated basin. Generally, basins with high form factor have high peak flows of short duration but elongated drainage basin with low form factor have lower peak flow of long duration.

\subsubsection{Drainage Density $(\mathrm{Dd})$}

Drainage density is the average length of streams within the basin per unit of area (Horton, 1945). It is a ratio between the total length of streams of all orders within a basin and the basin area (Horton, 1932; Deju, 1971). Horton (1932) also indicated that drainage density is an excellent indicator of the permeability of the surface of a drainage basin. Drainage density is the network extent and is of considerable hydrogeological and geomorphological significance since it is an index that measures both the nature of dissection within the basin and hydrogeological significant network (Gardiner, 1981). Results of the analysis of the drainage density of the Aynalem and Illala basins show 1.74 and $1.72 \mathrm{~km} / \mathrm{km} 2$ respectively (Table 4). The analysis result indicates a lower drainage density value that shows better infiltration in the study area.

\subsubsection{Stream Frequency (Fs)}

Stream frequency is defined as the number of streams of a given order per unit area (Horton, 1932, 1945). Stream frequency is used as a supplementary measure of the finesse of the texture of the topography. According to Melton (1958), two hypothetical basins having equal areas and an equal number of channel segments will have identical stream frequency. The stream frequency analysis result of the Aynalem and Illala basins is 1.64 and $1.73 \mathrm{no} / \mathrm{km} 2$. The result indicates a lower stream frequency characterized by low surface runoff, gentle slope surface, permeable subsurface material, vegetation, and high relief setting.

\subsubsection{Infiltration number (If)}

The infiltration number of a watershed is defined as the product of stream density and stream frequency and gives an idea about the infiltration characteristics of the catchment (Smith, 1950). 
The higher the If, the lower will be the infiltration capacity and the higher run-off. The analysis result of the Infiltration number of Aynalem and Illala basins is 2.85 and 2.97 respectively (Table 4). According to Tufa and Feyissa (2018) the analysis result of the infiltration ratio made for kito and Awetu sub-basins is 9.26 and 10.89 respectively. As compared to the works of Tufa and Feyissa (2018), the infiltration number of the study site (Aynalem and Illala) is relative with a very small value which indicates relatively higher infiltration capacity and little runoff.

\subsubsection{Length of overland flow $(\mathrm{Lg})$}

Length of overland flow is defined as the length of the flow of water over the ground before it gets concentrated into definite stream channels and in most cases, it is approximated by half the average distances between the stream channels and hence is approximately equal to half the reciprocal of the drainage density (Horton, 1945). It is an independent variable showing both hydrological and physiographical development of the drainage basin (Horton, 1945, Schumm, 1956). The analysis result from the Aynalem-Illalal streams is $0.29 \mathrm{~km}$. Higher values of length of overland flow indicate low relief and low value indicate higher relief. This value, therefore, indicates the two streams are very well-drained having low to moderate relief.

\subsubsection{Drainage texture $(\mathrm{Dt})$}

It is defined as the ratio between the numbers of streams to the perimeter of the basin (Smith, 1950). The drainage texture shows the relative spacing of the drainage lines (Horton, 1945). Drainage lines are more frequent and more active over the impermeable area than the permeable Horton (1945). According to Smith (1950) drainage texture classification drainage basin with $<2$ is very course, $2-4$ is course, $4-6$ is moderate, $6-8$ is fine, and $>8$ is very fine. The analysis result of the drainage texture of the Aynalem and Illala streams is 3.50 and 6.19 respectively (Table 4). Based on the drainage texture classification of the drainage texture of the Aynalem and Illala is course and fine texture respectively.

Table 4. Analysis result of areal aspect parameters of Ayanlem and Illala streams.

\begin{tabular}{|lllllllll|}
\hline Stream & $\begin{array}{l}\text { Elongation } \\
\text { Ratio } \\
(\boldsymbol{R e})\end{array}$ & $\begin{array}{l}\text { Circularity } \\
\text { Ratio }(\text { Rc })\end{array}$ & $\begin{array}{l}\text { Form } \\
\text { Factor } \\
(\boldsymbol{R f})\end{array}$ & $\begin{array}{l}\text { Stream } \\
\text { Density } \\
\boldsymbol{D d}\end{array}$ & $\begin{array}{l}\text { Stream } \\
\text { Frequency } \\
(\boldsymbol{F s})\end{array}$ & $\begin{array}{l}\text { Over } \\
\text { land } \\
\text { flow } \\
(\mathbf{L g})\end{array}$ & $\begin{array}{l}\text { Infiltration } \\
\text { Number } \\
(\boldsymbol{I F})\end{array}$ & $\begin{array}{l}\text { Stream } \\
\text { Texture } \\
(\boldsymbol{D})\end{array}$ \\
\hline Aynalem & 0.51 & 0.34 & 0.2 & 1.74 & 1.64 & 1.14 & 0.18 & 3.50 \\
\hline Illala & 0.56 & 0.47 & 0.24 & 1.72 & 1.73 & 1.47 & 0.12 & 6.19 \\
\hline
\end{tabular}




\subsection{Relief Aspects}

Under the relief aspect the morphometric parameters included are basin relief, relief ratio, ruggedness number and relative relief.

\subsubsection{Basin Relief $(\mathrm{H})$}

Basin relief is a parameter that shows the elevation difference between the highest and lowest point in the basin Hadley and (Schumm, 1961). It is also described as the vertical distance between the lowest and highest points of the watershed (Schumm, 1956). The results of the analysis show that basin relief of Aynalem and Illala is $750 \mathrm{~m}$ and $820 \mathrm{~m}$ respectively (Table 5).

\subsubsection{Relief Ratio $(\mathrm{Rh})$}

Relief ratio is defined as the ratio between the total relief of a basin and the highest point of a basin, and the longest dimension of the basin parallel to the principal drainage line (Schumm, 1956). The analysis result of the relief ratio for Aynalem and Illala is 0.025 and 0.022 respectively (Table 5). It is an indicator of the intensity of the erosional process operating on the slope of the basin (Schumm, 1956). It has been observed that there is a high degree of correlation between high relief, and high drainage frequency and high stream channel flow which brings out high discharge in short duration. It measures the overall steepness of the micro-watershed and is an indicator of the intensity of the soil erosion process operation on the watershed's slope (Schumm, 1956). The high value of relief ratio is the characteristics of the hilly area with high runoff production and soil erosion.

\subsubsection{Ruggedness Number (Rn)}

Strahler (1968) has described as the product of maximum basin relief and drainage density and it usually combines slope steepness with its length. The low ruggedness value of watershed implies that area is less prone to soil erosion and have intrinsic structural complexity in association with relief and drainage density.

Higher values shows uneven topography, lithological heterogeneity of terrain and high amount of dissection, moderate value indicate flat topped surface or ridge and valley topography and moderate to moderately high degree of dissection and lower values are found in areas of less dissection and leveled surface (Rao et al., 2017). In this study the ruggedness number value is 1.31 and 1.41 for Aynalem and Illala streams respectively (Table 5). According to Bhatt and Ahmed (2014) the analysis result of ruggedness value of the study area is moderate. The Aynalem 
and Ilalla stream indicates that partially, the flat top surface or ridges and valley topography and moderately higher degree of dissection and medium runoff is expected in these catchments.

\subsubsection{Relative relief (Rhp)}

It is defined as the ratio of maximum basin relief to the perimeter of the basin (Schumm, 1956; Melton, 1957). It represents a variation of altitude in a unit area with respect to the local base level. It is an essential morphometric variable used for the comprehensive assessment of morphological characteristics of the terrain. The analysis result of the study area in Aynalem and Illalala streams is 0.95 and $0.86 \mathrm{~m}$ respectively.

Table 5. Analysis result of relief aspect parameters of Ayanlem and illala streams.

\begin{tabular}{|llllll|}
\hline $\begin{array}{l}\text { Name of } \\
\text { Stream }\end{array}$ & $\begin{array}{l}\text { Basin Relief } \\
(\boldsymbol{H})(\boldsymbol{m})\end{array}$ & $\begin{array}{l}\text { Relief } \\
\text { Ratio }(\text { Rh })\end{array}$ & $\begin{array}{l}\text { Ruggedness } \\
\text { Number }(\text { Rn })\end{array}$ & $\begin{array}{l}\text { Relative Relief } \\
(\text { Rhp })(\boldsymbol{k m})\end{array}$ & $\begin{array}{l}\text { Hypsometric } \\
\text { Integral }\end{array}$ \\
\hline Aynalem & 750 & 0.025 & 1.31 & 0.95 & 0.57 \\
\hline Illala & 820 & 0.022 & 1.41 & 0.86 & 0.48 \\
\hline
\end{tabular}

\subsubsection{Hypsometric Analysis}

Hypsometry is the relative proportion of area at different elevations within a region. The hypsometric curve represents the relative proportion of the basin area below (or above) a given height (Strahler, 1952a; Hurtrez et al., 1999).

Reitter et al. (2002) has described that hypsometric curves and hypsometric integrals are important indicators of watershed conditions. Because the difference in the shape of the curve and hypsometric integral values are related to the degree of in equilibrium in the balance of erosive and tectonic forces (Weissel et al., 1994). The shape of the hypsometric curves explains the temporal changes in the slope of the original basin. Strahler (1952a) pointed out that based on the shape of the hypsometric curve basins are classified into three: young (convex up), mature (sshape), and old stages (Concave up).

The hypsometric integral which is expressed by percentage is an indicator of the remnants of the present volume as compare to the original volume of the basin. It also shows the cycle of erosion (Strahler, 1952a). Based on hypsometric integral the cycle of erosion is classified into three groups representing three distinctive stages of the geomorphic cycle i.e. HI <0.35 old stage; 0.35 0.6 mature stage and $\mathrm{HI}>0.60$ youthful condition. 
For both Aynalem-Illala streams and hypsometric parameters are calculated and hypsometric curves have been prepared (Fig $5 \mathrm{a} \& \mathrm{~b}$ ). The Aynalem stream curve is characterized by concave-convex shape with an average HI value of 0.57 indicating stream maturity. The Illala stream curve though distorted is also characterized by concave-convex shape with HI values of 0.48. This represents mature stage of landforms. That is both streams are characterized by fluvial and slope wash processes of landforms.

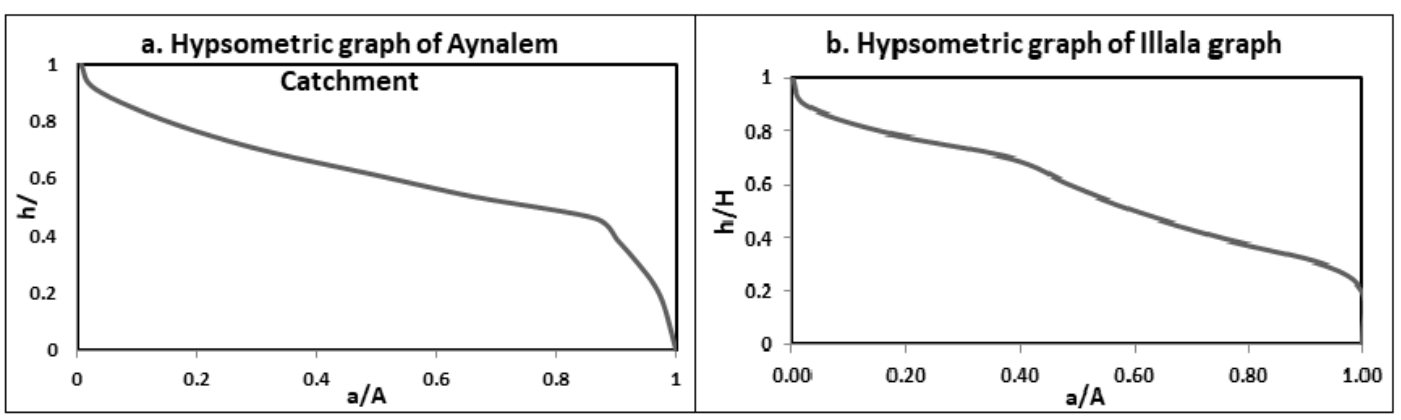

Figure 5. Hypsometric curve of a. Aynalem and b. Illala.

\section{CONCLUSION AND RECOMMENDATION}

In this study, efforts have made to evaluate morphometric parameters of Aynalem and Illala streams using Topo-map and GIS. Morphometric analysis was done for linear, areal, and relief aspects of the stream system. The Aynalem and Illala streams show fourth and fifth-order streams respectively. The result shows that the drainage network of the Aynalem area is structurally controlled and there is less integration between the streams of different orders. The bifurcation ratio of the Illala indicates the relatively mountainous and steeply sloped region.

The analysis result of elongation ratio, circularity ratio, and form factor of both streams (Aynalem and Illala) show an elongated stream. The streams are characterized by elongated streams system of low form factor and imply lower peak flow of long duration and easier for flood management. In addition, the analysis result of stream density, stream frequency, Infiltration number, and overland flow parameters revealed that in the area higher infiltration is favored than runoff. This is supported by the presence of a number of high yield wells within the two streams. This implies that the area is a proper area for managed aquifer recharge (artificial recharge). But when we compare Aynalem and Illala streams the first one is relative with better infiltration and less runoff, which is indicated in the infiltration number, overland flow, and drainage texture. 
Based on the hypsometric integral value we can conclude that the Aynalem stream is at the early maturity stage and the Illalla stream at the late stage maturity and both show S-shaped (concave) hypsometric curve indicate the mature stage of the development of the stream.

It is recommended that this work is better to related with soil texture, slope, aspect, vegetation cover and land use since these have direct impact on groundwater recharge.

\section{ACKNLOWLEDGEMENTS}

Authors acknowledge the anonymous reviewers whose comments have improved the quality of the paper quite significantly.

\section{CONFLICT OF INTERESTS}

There is no conflict of interests

\section{REFERENCE}

Abrahams, A.D \& Flint, J.J. 1983, Geological controls on the topological properties of the trellis channel networks. Geological Society of America Bulletin, 94: 80-91.

Ali, K., Bajracharya, R.M., Sitaula, B.K., Raut, N \& Koirala, H.L. 2017. Morphometric Analysis of Gilgit River Basin in Mountainous Region of Gilgit-Baltistan Province, Northern Pakistan. J. Geoscience and Environ. Protection, 5: 70-88 (doi: 10.4236/gep.2017.57008).

Altaf, F., Gowhar, M \& Shakil, A. R. 2013. Morphometric Analysis to Infer Hydrological Behaviour of Lidder Watershed, Western Himalaya, India. Geography J., 14: 178021.

Beyth, M., 1971. The Geology of Central and Western Tigray. Unpublished PhD dissertation. Report, Ethiopian Institute of Geological Survey (EIGS), Addis Ababa.

Beyth, M., 1972. Paleozoic sedimentary basin of Mekelle Outlier, Northern Ethiopia. American Association of Petroleum Geology Bulletin, 56: 2426-2439.

Beyth, M \& Shachnai, E., 1970. Hydrogeology of Mekelle area, Geological survey of Ethiopia, Addis Abeba, Ethiopia.

Bhatt, S \& Ahmed, S. A. 2014. Morphometric analysis to determine floods in the Upper Krishna basin using Cartosat DEM. Geocarto International, 29(8): 878-894 (doi: 10.1080/10106049.2013.868042). 
Biswas, S., Sudhakar, S \& Desai, V.R. 1999. Prioritization of subwatersheds based on morphometric analysis of drainage basin - A remote sensing and GIS approach. J. Indian Society of Remote Sensing, 27(3): 155-166.

Bosellini, A., Russo, A., Fantozzi, P. L., Getaneh, A \& Solomon, T. 1997. The Mesozoic succession of the Mekelle Outlier [Tigre Province, Ethiopia]. Memorie di Science Geologiche, 49: 95-116.

Burbank, D.W. 1992. Causes of recent Himalayan uplift deduced from deposited patterns in the Ganges basin. Nature, 357:.680-683.

Clarke, J.J. 1966. Morphology from maps, Essays in geomorphology. Elsevier Publishing Company, New York, pp. 235-274.

Daniel, J.R.K. 1981, Drainage density as an index of climatic geomorphology. Journal of Hydrology, 50: 147-154.

Deju, R.A. 1971. Regional hydrology fundamentals. Garden and Breach publications.

Dunne, T. 1980. Formation and controls of channel network. Progress in Physical Geography, 4: 211-239 (doi:10.1177/030913338000400204).

Fethangest, W. 2016. Hydrogeological Assessment of Fracture System in the rock mass of Mekelle Area (Ethiopia) Using Geo-statistical approach, $\mathrm{PhD}$ dissertations (unpubl.).

Gardiner, V. 1981. Drainage basin morphometry; In: Geomorphologieal techniques (ed.) A. Goudie, London, UK, Allen and Unwin, pp. 47-55.

Garland, C. R. 1980. Geology of the Adigrat Area. Ministry of Mines, Energy and Water Resources, Geological Survey of Ethiopia, Addis Ababa, Memoir No.1, 51p.

Gebre, T., Kibru, T., Tesfaye, S \& Taye, G. 2015. Analysis of Watershed Attributes for Water Resources Management Using GIS: The Case of Chelekot Micro-Watershed, Tigray, Ethiopia. J. Geographic Information System, 7: 177-190 (doi: 10.4236/jgis.2015.72015).

Gregory, K.J. 1976. Drainage networks and climate. In: E. Derbyshire (Ed.), Geomorphology and climate. Wiley, Chichester, pp.289-315.

Hadley, R \& Schumm, S.1961. Sediment Sources and Drainage Basin Characteristics in Upper Cheyenne River Basin. USGS Water-Supply Paper 1531-B, Washington DC, 198.

Horton, R. 1932. Drainage Basin Characteristics, Transactions. American Geophysical Union, 13: 350-361 (doi: 10.1029/TR013i001p00350). 
Horton, R.E. 1945. Erosional development of streams and drainage basins; Hydrophysical approach to quantitative morphology. Geol. Soc. Am. Bull., 56(3): 275-370.

Hurtrez, J. E., Sol, C \& Lucazeau, F. 1999. Effect of drainage area on hypsometry from an analysis of small-scale drainage basins in the Siwalik Hills (Central Nepal). Earth surface processes and landforms, 24: 799-808.

Kazmin V., 1972. The geology of Ethiopia. Note, Ethiopian Institute of Geological Surveys, No. 821-051-12, 208p.

Kirkby, M. J. 1976. Tests of the random network model and its application to basin hydrology. Earth Surface Process, 1: 197-212.

Levitte, D. 1970. The geology of central part of Mekelle sheet (ND37-11). Note, Ethiopian Institute of Geological Survey. No. 821-201-12, 66p.

Liaqat, A. K., Rao, A. K \& Himanshu, G. 2017. Morphometric Characterization of Yamuna River Basin around Agra, Firozabad and Etawah Districts, Uttar Pradesh using Remote sensing and GIS Techniques. International Advanced Research Journal in Science, Engineering and Technology (IARJSET), 4(5) ISSN (Online) 2393-8021.

Melton, M. A.1957. An analysis of the relations among elements of climate, surface properties, and geomorphology. DTIC Document.

Melton, M. A. 1958. Correlation Structures of Morphometric Properties of Drainage Systems and Their Controlling Agents. Journal of Geology, 66: 442-460.

Miller, V.C. 1953. A quantitative geomorphic study of drainage basin characteristics in the Clinch Mountain area of Virginia and Tennessee. PhD Thesis, Columbia University (Unpubl.).

Nag, S. K \& Lahiri, A. 2011. Morphometric Analysis of Dwarakeswar Watershed, Bankura district, West Bengal, India, Using Spatial information technology. International J. Water Resource and Env Engg., 3(10): 212-219 (http://www.academicjournals.org/IJWREE).

Panda, S. K \& Sukumar, B .2010. Delineation of Areas for Water Conservation in Peruvamba River basin, Kannur district, Kerala, Using Remote Sensing and GIS. International Journal of Geomatics and Geosciences, 1(1): 76-83.

Pike, R.J \& Wilson, S.E. 1971. Elevation-Relief Ratio, Hypsometric Integral and Geomorphic Area-Altitude Analysis. Geological Society of America Bulletin, 82, 1079-1084 (doi: 10.1130/00167606(1971)82[1079:ERHIAG]2.0.CO;2). 
Prakash, K., Mohanty, T., Pati, J.K., Singh, S \& Chaubey K. 2016. Morphometrics of the Jamini River Basin, Bundelkand Craton, Central India using remote sensing and GIS technique. Applied Water Science, (doi: 10.1007/s13201-016-0524-y).

Prakash, K., Rawat, D \& Singh, S. 2019. Morphometric analysis using SRTM and GIS in synergy with depiction: a case study of the Karmanasa River basin, north central India. Applied Water Science, 9: 13 (doi: 10.1007/s13201-018-0887-3).

Rao, M.P., Cook, B.I., Cook, E.R., D'Arrigo, R.D., Krusic, P.J., Anchukaitis, K.J., LeGrande, A.N., Buckley, B.M., Davi, N.K., Leland, C \& Griffin, K.L. 2017. European and Mediterranean hydroclimate responses to tropical volcanic forcing over the last millennium. Geophys. Res. Lett., 44(10): 5104-5112 (doi: 10.1002/2017GL073057).

Reitter, D.F., Kochel, R.C \& Miller, J.R. 2002. Process Geomorphology. McGraw Hill, Boston.

Sarangi, A., Bhattacharaya, A.K., Singh, A \& Singh, A.K. 2001. Use of geographical Information System (GIS) in assessing the erosion status of watersheds. Indian J. Soil. Conservation, 29(3): 190-195.

Schumm, S.A. 1956. Evolution of drainage systems and slopes in badlands at a Perth Amboy, New Jersey. Geological Society of America Bulletin, 67: 597-646.

Smith, K. G.1950. Standards for grading texture of erosional topography. American Journal of Science, 248(9): 655-668.

Strahler, A.N. 1952a. Hypsometric (Area Altitude) analysis of Erosional topography. Geological Society of America Bulletin, 63: 1117-1142.

Strahler, A.N. 1952b. Dynamic Basis of Geomorphology. Geological Society of America Bulletin, 63(9): 923-938.

Strahler, A. N. 1957. Quantitative analysis of watershed geomorphology. Transactions, American Geophysical Union, 38(6): 913-920 (doi: 10.1029/tr038i006p00913).

Strahler, A.1964. Quantitative Geomorphology of Drainage Basins and Channel Networks. In: V.T. Chow (Ed.), Handbook of Applied Hydrology, McGraw-Hill, New York.

Strahler, A.N. 1968. Quantitative Geomorphology. In: R.W.Fairbridge (Ed), The Encyclopedia of Geomorphology, Reinhold Book Crop, New York.

Teklay, Z. 2006. Conjugate use of surface and Groundwater of Aynalem area. MSc Thesis Mekelle University, Mekelle, Ethiopia (Unpubl.). 
Tesfamichael, G., Florimond, D., S., Miruts, H., Solomon, G., Kassa, A., Kurkura K., Abdulwassie, H., Jan, N \& Nurhussen T., 2010. Large-Scale Geological Mapping of the Geba Basin, Northern Ethiopia. Tigray. Tigray Livelihood Paper No. 9. VLIR- Mekelle University IUC Program.

Tesfamichael, G., Florimond De Smedt, Kristine, W., Solomon, G., Abdelwassie, H., Miruts, H., Kassa, A., Jozef, D \& Kindeya, G. 2017. Regional groundwater flow modeling of the Geba basin, northern Ethiopia. Journal of Hydrogeoly, 25: 639-655 (doi:10.1007/s10040-0161522-8).

Tesfaye, C \& Gebretsadik, E. 1979. Hydrogeological map of Mekelle with explanatory report. Geological Survey of Ethiopia, Addis Ababa.

Thomas, J., Joseph, S., Thrivikramji, K.P \& Abe, G. 2011. Morphometric Analysis of the Drainage System and Its Hydrological Implications in the Rain Shadow Regions, Kerala, India. Journal of Geographical Sciences, 21: 1077-1088.

Tufa, F. G \& Feyissa, T. A. 2018. Morphometric Analysis of Kito and Awetu Sub Basins Jimma, Ethiopia. American Journal of Water Science and Engineering, 4(3): 80-90 (doi: 10.11648/j.ajwse.20180403.14).

USDA (United States Department of Agriculture). 1999. Natural Resources Conservation Service, Soil Taxonomy: A basic system of Soil classification for Making and Interpreting Soil Surveys, 2nd edition, Soil survey staff, U.S. Dept. of Agriculture Handbook Number 436,870p.

Venkateswaran, S., Vijay Prabhu, M., Suresh, M \& Suresh, R. 2012. Morphometric analysis for characterizing landforms study on Sarabanga Sub-basin, Cauvery River, Tamil Nadu, India. Inter. J. Lakes and Rivers, 5: 133-140.

Weissel, J. K., Pratson, L. F \& Malinverno, A. 1994. The length-scaling properties of topography. Journal of Geophysical Research, 99: 13997-14012.

Wisler, C.O \& Brater, B.F. 1959. Hydrology. Wiley, New York, 408p.

Worash, G \& Valera, R. 2001. Rare earth element geochemistry of the Antalo Supersequence in the Mekele Outlier (Tigray region, northern Ethiopia). Chem. Geol. 182: 395-407.

WWDSE. 2007. Evaluation of Aynalem well field and selection of additional prospective boreholes for Mekelle Town Water supply source. Report, volume II, 140p. 